\title{
O NORTE DE SUR E AS CONDICIONANTES PARA MANTER-SE NO CENTRO: O CASO DE MARÍA LUISA BOMBAL
}

\author{
Andrea Cristiane Kahmann ${ }^{8}$
}

Resumo: Este ensaio compila dados de vida e obra de María Luisa Bombal, escritora chilena impulsionada à fama pela revista Sur na Buenos Aires dos finais dos anos 1930, ápice do modernismo literário argentino, para, a partir dela, estabelecer uma crítica sócio-histórica sobre as condicionantes de aceitação e rejeição de uma obra literária por características e feitos de seu autor. Para além do óbvio representado por gênero e cor, propõe-se uma crítica da fortuna literária calcada em acesso a círculos restritos que se reconhecem mutuamente com base em sobrenome e origens, estruturas simbólicas e seus mecanismos de sanções e recompensas. No decorrer dessas páginas, e a partir da inclusão / exclusão de María Luisa Bombal no cânone ditado pelo grupo em torno à revista Sur, entre os anos 1930 e 1940, e trazendo o debate à atualidade, reflete-se sobre as mudanças nas relações centro x periferia, representados por Europa e América Latina, e as transformações teóricas da literatura como campo de estudo.

Palavras-chave: María Luisa Bombal. Revista Sur. Modernismo literário argentino. Crítica sócio-histórica.

Resumen: Este ensayo compila datos de vida y obra de María Luisa Bombal, escritora chilena impulsada hacia la fama por la revista Sur de Buenos Aires a finales de los años 1930, cumbre del modernismo literario argentino, para, a partir de ella, plantear una crítica sociohistórica sobre las condicionantes de aceptación o rechazo de una obra literaria por características y hechos de su autor. Más allá de lo obvio representado por género y color, se propone una crítica de fortuna literaria por acceso a círculos restrictos que se reconocen mutuamente con base en apellido y alcurnia, estructuras simbólicas y sus mecanismos de sanciones y recompensas. A lo largo de esas páginas, y con base en la inclusión /

${ }^{8}$ Doutora em Letras pela Universidade Federal do Rio Grande do Sul. Professora do Curso de Bacharelado em Letras Tradução Espanhol / Português da Universidade Federal de Pelotas. 


\section{0 | Andrea Cristiane Kahmann}

exclusión de María Luisa Bombal en el canon dictado por el grupo en torno a la revista Sur, entre los años 1930 y 1940, y llegando hasta los días de hoy, se construye una reflexión sobre los cambios de las relaciones centro x periferia, representados por Europa y América Latina, y las transformaciones teóricas de la literatura como campo de estudio.

Palabras clave: María Luisa Bombal. Revista Sur. Modernismo literario argentino. Crítica sociohistórica.

Embora tenha falecido aos setenta anos e começado a publicar muito jovem, o inventário da literatura de María Luisa Bombal publicada em língua espanhola computa cinco contos, três crônicas e duas novelas. Apesar de tão escassas publicações, sua escrita foi celebrada pela crítica que nela identificava a polissemia e a iconoclastia da ruptura necessária com os padrões estéticos da sua época. Para García Márquez, foi ela quem deu o traço pioneiro do realismo mágico, no que foi seguida por Rulfo, que a leu e a admirou e encontrou na escrita de Bombal a inspiração para muitas ruas da sua Comala (apud VERDUGO FUENTES, 2013). No Brasil, que historicamente pouco traduz dos vizinhos latino-americanos, o nome de María Luisa Bombal circula (ou já circulou) nas capas de, pelo menos, quatro edições comerciais: Entre a vida e o sonho (tradução de House of mist, por Carlos Lacerda, para a editora Irmãos Pongetti, em 1949); A última névoa (La última niebla), publicada pela Difel, em 1985, e apresentando Neide T. M. González como tradutora; A amortalhada (La amortajada), de 1986, traduzida por Aurora Fornoni Bernardini e Alicia Ferrari del Pardo, também para a Difel; e a edição de 2013, que compila A última névoa e A amortalhada, em retradução de Laura Janina Hosiasson para a Cosac Naify. O objetivo deste artigo, no entanto, não é o reforço laudatório das qualidades estéticas (inegáveis) da escritora nascida no Chile mas impulsionada à fama na Buenos Aires da década de 1930. Nem tampouco se pretende analisar as traduções e os tradutores de María Luisa Bombal no Brasil, o que já foi objeto da tese doutoral defendida na Universidade Federal do Rio Grande do Sul (KAHMANN, 2017). Neste momento, e tendo como base as reflexões de Sergio Miceli em Sonhos da periferia (2018), propõe-se uma crítica das disputas pelas posições de centralidade no campo literário, das condicionantes de aceitação ou rejeição de um autor por força das trocas simbólicas, das disputas de mercado, das afiliações políticas e, em última análise, dos mecanismos de 
O norte de Sur e as condicionantes para manter-se no centro: O caso de María Luisa Bombal | 31 constrangimentos e recompensas calcados em elementos exteriores à suposta qualidade literária.

Para tanto, primeiro é preciso recordar que, da escassa obra de María Luisa Bombal, uma novela, La amortajada (de 1938), dois contos Las islas nuevas e El árbol (ambos de 1939) e uma crônica poética, Washington, ciudad de las ardillas (de 1943), foram publicadas na revista Sur (1931 - 1991), inicialmente sob a direção de Victoria Ocampo, “a primeira mulher que toma uma iniciativa cultural-institucional que afeta destinos intelectuais masculinos" (SARLO, 2010, pp. 49 - 50), sempre tendo por respaldo sua condição primordial de classe.

Sur iniciou suas atividades na casa de Victoria em Palermo Chico, um dos bairros mais nobres de Buenos Aires, e depois foi transferida para outras propriedades da família Ocampo. A diretora, fundadora e mecenas da revista escolheu os integrantes do conselho de direção entre suas relações pessoais e não apenas decidia sobre as colaborações como frequentemente escrevia ela própria contribuições para sua revista (GRAMUGLIO, 2007).

Apesar de seu nome, Sur [Sul, em tradução ao português], em Carta a Waldo Frank, que abre o primeiro número da revista, no verão de 1931, Victoria Ocampo procurou desfazer uma possível "falsa interpretação": contava que, em Paris, lhe teriam questionado se sua revista pretendia dar as costas à Europa. "Dar as costas à Europa? Percebem o ridículo infinito dessa frase?" (OCAMPO, 1931, p. 11, a tradução é minha). A diretora, então, esclareceu que o nome Sur havia sido escolhido por Ortega y Gasset, a quem pediu auxílio por telefone, porque "essa gente [os espanhóis] têm o costume de nos batizar" (OCAMPO, 1931, p. 13, a tradução é minha). A Europa laureada pela revista, no entanto, era a que recebia os criollos argentinos para elevá-los na ordem simbólica das coisas, e não a que expulsava imigrantes cujos filhos vinham inflacionar as disputas por espaços nas universidades e profissões liberais e desestabilizar os privilégios das elites tradicionais portenhas no acesso e na fruição de capital e bens simbólicos. A esse segundo grupo, o dos ascendentes, o dos imigrantes, a que pertenciam, por exemplo, Roberto Arlt, Horacio Quiroga e Alfonsina Storni, que haviam conquistado boa recepção na mídia impressa e na indústria cultural, a revista Sur dedicaria o descrédito (MICELI, 2018). Para Miceli, essa exclusão não se sustentaria em razões de gosto ou de ordem apenas literária; para ele é "insensato dissociar a ressonância da revista das condições privilegiadas de liquidez financeira, 


\title{
32 | Andrea Cristiane Kahmann
}

bem maior, como se verá, do que as margens de respiro intelectual e político" (MICELI, 2018, p. 43).

A revista capitaneada por Victoria Ocampo arregimentou "o patriciado portenho, o café society vanguardista, extasiado por arte e literatura, e figuras conspícuas da direita católica, antimoderna" (MICELI, 2018, p. 39) ainda no rescaldo da crise mundial de 1929 e da destituição de Yrigoyen pelos militares sob o comando de Uriburu. Embora colaboradores de diversas extrações sociais e posições econômicas tenham formado subgrupos com posicionamentos ideológicos e estéticos que nem sempre conviveram de forma harmônica, é possível encontrar, no interior da revista, "em meio à diversidade de condições e de trajetórias, um perfil indicativo de certas disposições comuns, próprias aos descendentes de famílias educadas e fixadas no país por várias gerações" (GRAMUGLIO, 2007, p. 54). Tratava-se de um perfil não óbvio numa Buenos Aires em mutação, uma cidade que havia duplicado a sua população em menos de um quarto de século e onde, em 1936, os homens não nativos superavam em 120,9\% os nativos (SARLO, 2010, p. 38). A demografia desestabilizava os padrões de gosto e de consumo da literatura, e parte do mercado editorial argentino desviou-se dos señores para as camadas médias. Sur, no entanto, negou-se a essa postura. Segundo Miceli:

\begin{abstract}
A revista cumpriu as funções de banco central da cultura grã-fina, dispensando incentivos e legitimidade aos escritores próximos ao corpo restrito de editores: manejou as redes de aliança e proteção mútua pelo intercâmbio de resenhas e pleitos de reverência; regulou cotações no mercado de credenciais e de notoriedade; condenou ao descrédito e à relegação as obras e reputação de escritores concorrentes (MICELI, 2018, p. 42-43).
\end{abstract}

Em regra, os integrantes de Sur não mantiveram vínculos visíveis com partidos políticos nem pertenceram a instituições estatais (GRAMUGLIO, 2007) e, na década de 1930, quando a Argentina vivia imersa na recessão econômica, na repressão política e na fraude eleitoral, e o mundo assistia estupefato ao avanço dos regimes totalitários e à Guerra Civil Espanhola, Sur esforçava-se por manter-se entrincheirada na construção utópica de uma literatura pura. Para Miceli, é bastante sintomático que, no centro de uma Argentina em pleno estado de sítio, testemunhando a prisão de intelectuais e políticos, o cerco à imprensa, as 
greves gerais e o assassinato de parlamentares, a revista tenha conservado a postura olímpica de abstenção (MICELI, 2018, p. 39).

Quanto a María Luisa Bombal, não só a revista escolhida para suas publicações, mas também o momento histórico em que elas ocorreram foram bastante relevantes para a sua inclusão (ainda que fugaz) no centro do campo de forças da literatura de prestígio. Não custa repetir que, ao mencioná-lo, não se refuta a força narrativa de Bombal. Com Enrique Imbert (2000, p. 252), em sua História de la literatura hispanoamericana, cabe reconhecer que: "Se iniciarmos com narrativas não-realistas, o nome principal é o de María Luisa Bombal (...) em que o humano e o sobrehumano aparecem em uma zona mágica, poética pela força da visão, e não por truques de estilo" [a tradução é minha]. Contudo, faz-se necessário analisar as engrenagens do sistema que, em determinado momento histórico, ungiu a escritora, para que se possa compreender porque, em seguida, o mesmo sistema a relegou ao esquecimento.

É possivel exemplificar o mote deste artigo com o fato de que, no Brasil de 2014, Márcia Tiburi, encarregada de elaborar resenha sobre a retradução de Laura Janina Hosiasson para o Blog da Cosac Naify, não se furtou de mencionar aquela que, talvez, seja a mais imediata credencial da qualidade literária de María Luisa Bombal: "A orelha é de ninguém menos que Jorge Luis Borges!” (TIBURI, 2014). Trata-se de um evento exterior à percepção de mérito literário mas bastante ilustrativo para a análise focada nos sistemas e na interferência de elementos extraliterários a margearem a escolha da obra a traduzir e bem assim a sua recepção. De fato, nas republicações de Bombal posteriores a 1977 consultadas por Kahmann (2017), as palavras de Jorge Luis Borges elogiando a amiga chilena constam como orelha, contracapa ou prefácio. O escritor argentino, já famoso expoente das letras mundiais, teria atendido ao pedido feito por meio da seguinte carta (inclusa em BOMBAL, 1996, p. 372) que traduzi ao português:

Viña del Mar, 12 de dezembro de 1977

Georgie, querido:

Se soubesses o quanto me lembro de ti, ainda que não o pareça. Mas bem sabes que sou tão parca para minhas cartas quanto sou para minhas novelas.

Esta carta tem seu interesse. Peço que atendas ao pedido do meu amigo e representante Richard Cunningham. É 
importante para mim, bem te darás conta, oh, monstro sagrado!

Esse vai ser, seguramente, o melhor presente de Ano Novo que me vai fazer* brindar.

Abraça-te,

María Luisa

Ps: Desculpa erratas*

María Luisa e Jorge Luis (a quem ela chamava simplesmente Georgie, tal qual a mãe do escritor) compartilhavam o gosto pelo cinema e os restaurantes onde se tocavam bons tangos. Foram grandes companheiros entre 1938 e 1939, período de ascensão dos fascismos em que a revista se converte em trincheira da pura literatura. Nesses anos, a chilena publicaria em Sur a sua segunda novela, A amortalhada, e dois de seus cinco contos, vindo a compor a "confraria borgiana" (MICELI, 2018, p. 75) que determinou uma guinada literária na vocação antes ensaística da revista portenha. Tratava-se da consolidação de um movimento que rechaçava quaisquer influências extraliterárias (da história ou da sociologia, por exemplo) na apreciação do mérito e da literatura em si. A criação de Bombal, assim como a de José Bianco, Bioy Casares, Silvina Ocampo e outros acólitos de Borges, vinha a calhar na redefinição de um projeto estético para uma revista que se obstinava em manter-se à margem das crises políticas mundiais enquanto disseminava uma literatura feita por e para o velho dinheiro. Tal como a de Borges, a narrativa dos discípulos deste, que compuseram a fornada de escritores incensados por quem fazia crítica literária em meio à guerra, pressupunha, conforme Miceli, leitores seletos, cúmplices dos padrões de gosto, afeitos aos estrangeirismos e com "domínio da tradição literária, das cifras capazes de deslindar enigmas compartilhados no círculo de sociabilidade" (MICELI, 2018, p. 79). Enfim, tratava-se de uma literatura que pressupunha um leitor "capaz de enfiar a segunda pele do privilégio por merecimento" (MICELI, 2018, p. 79).

María Luisa Bombal Anthes, nascida em 8 de junho de 1910 no exclusivo balneário chileno de Viña del Mar, atendia aos pressupostos de origem para integrar o seleto grupo em torno da revista Sur. Tinha predileção por destacar sua genealogia aristocrática e a forte presença estrangeira em sua casa. Quando instigada a falar de si, podia desfiar um rosário de nomes e feitos aos quais se vinculava por parentesco, como, por exemplo, recordar que o "primeiro cônsul alemão em Santiago foi meu 
bisavô e seu sobrenome era Precht" (BOMBAL, 1996, p. 46, tradução minha). Esclarecia descender, pelo lado paterno, de argentinos fugidos do caudilho Juan Manuel de Rosas (1793 - 1877); e, por parte de mãe, de huguenotes franceses emigrados para a Alsácia (BOMBAL, 1996, p. 321). Ela afirmava ser parente do médico que teria matado Tchekov (BOMBAL, 1996, p. 46). O que se sabe é que era tia de Carlos Bombal, quem, de 1974 a 1976, foi chefe do gabinete do reitor da Pontifícia Universidade Católica do Chile, período em que ele teria colaborado com a polícia política de Pinochet e concorrido para a prisão do professor Alejandro Ávalos Davidson e talvez outros dentre os 28 mortos ou desaparecidos políticos da universidade (conforme PROYECTO INTERNACIONAL DE DERECHOS HUMANOS). Era de se esperar que os representantes de uma elite vivendo a derrocada de seus privilégios, como eram os Bombal, manifestassem o apoio explícito ao golpe de 11 de setembro de 1973 e com ele colaborassem. Em entrevista concedida por María Luisa ao jornal La Patria em 21 de abril de 1974, ao ser questionada sobre como se sentia de voltar ao Chile, a escritora respondeu:

$\mathrm{Na}$ minha viagem anterior, eu o encontrei a ponto de não ser mais o Chile. Não era mais o nosso país, mas um feudo. (...) Agora voltamos a ser o Chile - prossegue -. Muito simples; nos salvamos, somos um país. Gosto do nosso governo: é democrático, estrito, eficiente, respeitoso com os direitos humanos. Devo dizer que não eu acreditava que fosse um dia assistir à união, à luta e à devoção de pessoas de ideias diferentes, de classes diferentes, e se integrando com tanta intensidade e paixão para defender seu país da queda no vazio. Tudo que dizem lá fora é uma injustiça, é produto da ignorância e de calúnias premeditadas por forças às que não é preciso dar nome (BOMBAL, 1996, p. 418, tradução minha).

Esse discurso, porém, relacionava-se mais às lentes de classe que a qualquer dado de realidade a indicar melhoria nas condições de vida da sociedade civil que conferiu o sustentáculo ideológico à ditadura. Em 3 de agosto de 1974, em carta à irmã, María Luisa denunciaria o crescente custo de vida; eram os primeiros tempos das profundas mudanças implementadas por economistas de orientação liberal pró-mercado 


\section{6 | Andrea Cristiane Kahmann}

identificados com o viés ideológico representado pela Universidade de Chicago, marcantes presenças ao longo de toda a era Pinochet (conforme BIBLIOTECA NACIONAL DE CHILE). O desemprego massivo, a diminuição dos salários e o aumento dos preços dos serviços e mercadorias internacionalizadas em contexto agravado pela hiperinflação fizeram parte do cenário desta ditadura que deixou como herança um percentual aproximado de $40 \%$ dos chilenos abaixo da linha de pobreza (39\%, conforme LARRAÑAGA, 2010). María Luisa percebia os primeiros sintomas da crise que só viria a se agravar, mas não se eximiria de redigir ufanistas linhas sobre a Junta Militar:

Fecharam a metade do departamento por causa do frio, que é um problema sério em todo o país. E a eletricidade, o gás liquefeito, a calefação custam fortunas se puderes dar-te ao luxo de usá-los como é devido. Vivemos a meio calor, a meia luz e tiritando de frio. A vida anda nas nuvens - quer dizer, comida, vestuário, transporte, remédios, cabelereiro, hotéis, horror. Mas temos de tudo, e ordem e tranquilidade, e o Chile se vai refazendo de modo lento e seguro. A Junta é muito inteligente, serena e justa, e não existe chileno que não esteja de acordo com o que digo, chileno seja da classe a que pertencer (BOMBAL, 1996, p. 363 - a tradução é minha; os grifos estão presentes no original).

Em julho de 1978, Aurora Fornoni Bernardini e Lidia Neghme Echeverría realizaram uma entrevista com María Luisa Bombal, e espantaram-se com sua situação da escritora:

Encontramos a autora num salão de chá, em Santiago, em condições de vida bastante precárias. Encontrava-se ela em difíceis condições financeiras, por não conseguir receber uma aposentadoria nem do marido (francês naturalizado norte-americano), nem do governo chileno, que, devido à incompreensão de comissões burocráticas, não lhe outorgou o Prêmio Nacional de Literatura (BERNARDINI, 1986, p. X).

A cada ano, nas cartas a sua irmã, María Luisa especulava a possibilidade de que, enfim, lhe concedessem o Prêmio Nacional de Literatura; nunca o recebeu. Apesar dos vínculos familiares com membros 
O norte de Sur e as condicionantes para manter-se no centro: O caso de María Luisa Bombal | 37 do governo e das loas constantes à ditadura, não houve quem por ela intercedesse nas questões relativas à aposentadoria ou do reconhecimento à sua obra. Os jurados chilenos nunca haviam sido simpáticos às mulheres escritoras; Gabriela Mistral, por exemplo, só foi agraciada com este prêmio em seu país em 1951, seis anos depois de ter recebido o Prêmio Nobel. Na era de Pinochet, a situação das mulheres, ainda que amparadas em sobrenomes de prestígio ou no apoio ideológico ao regime, não viria a melhorar.

Assim, em 1977, sem ter publicado mais nada, viúva e necessitada de recursos, foi por intermédio de Lucía Guerra, catedrática de Literatura Latino-americana na Universidade da Califórnia, que María Luisa conseguiu a oportunidade de ver-se reeditada nos Estados Unidos e, com isso, obter algum dinheiro. Foi para essa edição que solicitou ao antigo amigo Jorge Luis Borges que redigisse a apresentação que impressionou Márcia Tiburi e outros críticos sensíveis ao capital simbólico do escritor argentino. $\mathrm{Na}$ edição norte-americana, capitaneada por Richard Cunningham, marido de Lucía Guerra, lia-se por primeira vez:

Quando em Santiago do Chile ou Buenos Aires, em Caracas ou Lima se nomeiam os melhores nomes, nunca falta o de María Luisa Bombal. Esse fato é ainda mais notável se considerarmos a brevidade de sua obra, que não corresponde a nenhuma escola determinada e, afortunadamente, costuma carecer de cor local.

Agradeço à minha sorte que nossos caminhos se tenham cruzado há tantos anos já, e que agora eu possa dizê-lo publicamente e apresentar aos leitores da outra América esta íntima amiga e grande escritora chilena (BOMBAL, 1996, p. 51).

As generosas palavras de Borges em 1977 deviam-se (o texto deixa claro) aos caminhos que, "por sorte", se tinham cruzado "há tantos anos já”. Fazia quase quarenta anos, de fato, que María Luisa Bombal havia frequentado aquele seleto grupo da revista Sur em Buenos Aires. No entanto, se os anos de 1938 a 1940 tinham sido de "íntima amizade" com Borges e sua "confraria", o mês de janeiro de 1941 testemunharia o episódio que macularia para sempre a carreira da escritora: María Luisa atentou contra Eulogio Sánchez, seu antigo amante. Sem saber que ele se tinha casado novamente e lidando com progressivas dificuldades com o 


\title{
38 | Andrea Cristiane Kahmann
}

alcoolismo, María Luisa, que andava armada, teve um ímpeto de desatino ao vê-lo acompanhado. Mesmo que a chilena não tivesse ainda traduções circulando no Brasil, tratava-se este de um crime tão extraordinário que o jornal brasileiro Correio da Manhã de 28 de janeiro de 1941 noticiaria:

\section{NO EXTERIOR \\ UM CRIME SENSACIONAL NA CAPITAL CHILENA \\ Santiago do Chile, 27 (U. P.) - A famosa escriptora Maria Luisa Bombal deu hoje quatro tiros de revolver no "general" Eulogio Sanchez Errazurir, fundador da Milícia Republicana e conhecido engenheiro. \\ A victima foi attingida no peito e no estomago. \\ O crime teve logar na esquina formada pelas ruas Augustinas e Banderas.}

Eulogio Sánchez decidiu não representar contra sua agressora, e Bombal foi conduzida à Casa Correccional de Mujeres (GUERRA, 2012). Muitos amigos intercederam por ela junto ao governo chileno, sobretudo Pablo Neruda e Gabriela Mistral (VERDUGO FUENTES, 2013). Em 1942, após se desenredar dos trâmites jurídicos, ela conseguiu partir aos Estados Unidos, onde três décadas de autoexílio a esperavam para exorcizar esses fantasmas.

María Luisa Bombal se havia feito escritora num mundo de Letras já aberto às mulheres, mas que delas ainda exigia que escrevessem (e se portassem) como mulheres. $\mathrm{Na}$ análise de Beatriz Sarlo sobre a modernidade periférica representada pela Buenos Aires das décadas de 1920 e 1930, tem-se que:

\begin{abstract}
Apesar de já ser admissível que as mulheres escrevam, elas devem fazê-lo como mulheres, ou melhor, destacando que, ao escrever, não contradizem a característica básica de seu sexo. O homem é cultura, a mulher natureza. A mulher corrige as operações que o homem realiza com a cultura (partir, enfrentar os outros com ismos e tendências): ela não divide, conserva; age no rio da evolução e não na torrente da quebra (SARLO, 2010, p. 130).
\end{abstract}

María Luisa Bombal, num desatino, e num momento histórico de retomada de extremo conservadorismo, havia agido contra o rio da evolução, havia quebrado uma regra implícita da pura literatura feita pelas 
O norte de Sur e as condicionantes para manter-se no centro: O caso de María Luisa Bombal | 39 mulheres do período: a de, não só na voz narrativa, mas também na vida real, ser puro amor, puro perdão, pura submissão. A confraria em torno de Jorge Luis Borges poderia até interceder pela liberdade da escritora junto ao governo chileno, mas não poderia seguir concedendo-lhe espaço numa revista que operava como "um círculo de sociabilidade da alta burguesia” (MICELI, 2018, p. 42) nem nas publicações em livro capitaneadas pela mesma grã-finagem. Não é de se estranhar, portanto, que o nome de María Luisa Bombal tenha sido retirado da Antologia da literatura fantástica, organizada por Jorge Luis Borges em companhia do casal Adolfo Bioy Casares e Silvina Ocampo. Se, na primeira edição da antologia, publicada em 1940, constava um conto de María Luisa Bombal, na segunda edição este - curiosamente - desapareceu! O exemplar circulante no Brasil, uma tradução de Josely Vianna Baptista, publicado em 2013 pela editora Cosac Naify, certamente tomando por original as edições portenhas mais recentes, não inclui o conto de María Luisa Bombal. O posfácio de Walter Carlos Costa (2013, pp. 429 - 434) a essa edição brasileira, sugere que a inclusão da escritora chilena no primeiro número da Antologia da literatura fantástica tenha sido influência de Silvina Ocampo, quem pode ter sido ofuscada por Borges e Bioy Casares quando da reedição. Seguindo a esteira de Miceli (2018), no entanto, e considerando a biografia de María Luisa Bombal, é possível especular uma correlação entre o envolvimento da escritora em um crime e a retirada de seu conto da obra organizada por e para o séquito de leitores da tradicionalíssima elite portenha.

Washington, ciudad de las ardillas, uma crônica poética concebida quando María Luisa já estava vivendo nos Estados Unidos, chegou a ser publicada na revista Sur, n. 106, em setembro de 1943. Essa pode ter sido uma última concessão do grupo à escritora que conheceu e frequentou a casa de Jorge Luis Borges e bem assim conviveu intimamente com Victoria Ocampo e o casal Adolfo Bioy Casares e Silvina Ocampo, Oliverio Girondo e Norah Lange, além de Amado Alonso, Matos Rodríguez (o autor de La Cumparsita) e com todo o círculo de famosos pintores em torno ao artista plástico Jorge Larco, que veio a ser o primeiro marido da chilena (BOMBAL, 1996, p. 330). Pode também, pela data, indicar uma predisposição da revista em possibilitar, sem romper com seu pacto de neutralidade literária, espaço à poetização da capital da nação que parecia estar despontando como provável vencedora da Segunda Guerra e novo Império a que idolatrar. 
Se essa publicação de 1943 encerraria, definitivamente, a presença de María Luisa Bombal junto ao restrito círculo da revista Sur, foi a partir da nova morada da autora, os Estados Unidos, que as portas do Brasil, costumeiramente fechadas aos vizinhos latino-americanos, se abririam e ela. Residente em Nova York, Bombal concedeu uma entrevista ao jornalista Germán Ewart; nela dizia que "o ambiente literário dos Estados Unidos é um vespeiro de ignorância e maldade, com desdém por tudo que seja latino-americano" (BOMBAL, 1996, p. 398, tradução minha). Ainda assim, a escritora conseguiu publicar pela Farrar Straus \& Giroux o romance House of mist, uma auto-adaptação de La última niebla para o público norte-americano. Para ser aceita no novo campo editorial, Bombal precisou converter uma novela de quarenta e cinco páginas ( $\mathrm{La}$ última niebla) em um romance de duzentas páginas (House of mist). Mais que isso: teve de alterar o final da trama, a pedido do agente literário, que lhe teria dito a respeito de A última névoa: "Muito bonito, mas é demasiado curto, e não vamos publicar um poema em prosa. Esclareça o assunto: afinal, a protagonista sonhou ou não sonhou? Dê um final para a história" (BOMBAL, 1996, p. 397, tradução minha). O novo final elaborado para House of mist não é, contudo, um esclarecimento à trama de La última niebla, pois os personagens são outros, suas motivações são outras e as tramas são independentes. Não se tratou, portanto, de uma tradução entre línguas e culturas, mas de uma nova criação para uma instituição diferente, com diferentes mecanismos de atuação do mecenato. House of mist não visaria àquela modernidade estrangeirizada e fervorosamente devota da pura literatura do grupo Sur, mas a um horizonte de expectativa composto sobretudo por donas de casa de uma América em pleno macartismo, neurótica com a caça aos comunistas e consumindo tramas sem complexidade para preencher o tempo livre das donas de casa já bem fornidas de eletrodomésticos para a limpeza, mas ainda sem televisão. Essa versão em inglês, apesar de constituir não uma tradução, mas uma nova narrativa, foi ignorada pelos críticos literários. Nem mesmo Lucía Guerra (quem, em 2012, traduziu essa nova obra ao espanhol sob o título La casa de niebla) a incluiria nas Obras completas de 1996.

Contudo, foi a partir dessa nova criação - em inglês - feita para a América macartista que María Luisa Bombal ingressaria em tradução no sistema literário brasileiro. Seu tradutor não era ninguém menos que Carlos Lacerda, então vereador pela UDN (União Democrática Nacional), partido ultraconservador. A edição de 1949 para a Irmãos 
O norte de Sur e as condicionantes para manter-se no centro: O caso de María Luisa Bombal | 41

Pongetti recebeu o título Entre a vida e o sonho, sugerindo que, para o público do Brasil, não bastava solucionar o final da trama; também seus títulos deveriam ser esclarecidos. E assim como todas as edições posteriores a 1977 incluiriam as palavras elogiosas de Borges à amiga, no Brasil de 1949, se destacaria o fato de a autora viver nos Estados Unidos. Como exemplo: às páginas 8 e 9 do Jornal de Notícias de 20 de fevereiro de 1949, na coluna "Vida literária no Brasil e no mundo", em meio a um artigo intitulado "A França e os Homens de Côr", e notícias sobre a UDN e o queremismo, havia o quadro "em poucas linhas", que apregoava: "O romance 'Entre a vida e o sonho', de María Luisa Bombal, traduzido ao português por Carlos Lacerda, foi selecionado pela empresa "Livro do Mês'. A autora é chilena, mas reside há anos nos Estados Unidos”.

As novelas de María Luisa Bombal mais aclamadas pela crítica, La última niebla e La amortajada, publicadas, respectivamente em 1934 e 1938, ingressariam em tradução no sistema brasileiro apenas após a morte da autora. Em compensação, o seu House of mist, de clara vocação comercial e publicado nos Estados Unidos, foi quase imediatamente traduzido para os leitores brasileiros. Tal fenômeno não pode ser explicado pelo mérito literário em que se aferrava a infantaria intelectual da revista Sur. Aliás, tampouco se pode, por esse construto, explicar como Jorge Luis Borges e seu Ficções (1944), livro tão consagrado na Argentina, somente em 1970 tenham recebido a tradução primeira de Carlos Nejar para o Brasil (VALLERIUS, 2010, p. 222). A constatação de Denise Vallerius implica reconhecer que apenas quando as traduções francesas e inglesas já haviam canonizado o escritor portenho, Borges recebeu tradução em livro no Brasil. Em outras palavras: "para que Borges adentrasse o mercado editorial brasileiro, necessitou, primeiramente, ser reconhecido pelo eixo euro-norte-americano" (VALLERIUS, 2010, p. 215). A pura literatura dos asseclas da revista Sur parece conformar um manto que se veste apenas quando convém.

O fenômeno das décadas de 1960 e 1970, que catapultaram autores latino-americanos como Jorge Luis Borges ao renome internacional, tampouco se explica pelo mérito literário puro e simples. $\mathrm{O}$ chamado boom da literatura latino-americana, caracterizado pelo inédito interesse estrangeiro na tradução de autores da América Latina, recebeu diferentes interpretações por parte da crítica. Segundo Marie-Hélène Catherine Torres $(2014$, p. 56 - 57), o boom estaria associado à criação, em 1954, de um Instituto de Altos Estudos da América Latina, em Paris, e ao acento político à cooperação após os golpes de Estado que 


\section{2 | Andrea Cristiane Kahmann}

massacraram diversos países e o consequente exílio em massa para a França. Também pode ser que, conforme análise de Eric Hobsbawm (1995, p. 485) tenha sido "o júri do Prêmio Nobel de literatura, um corpo cujo senso político em geral é mais interessante que seus julgamentos literários" que tenha conferido prestígio às letras latino-americanas. Gabriela Mistral já tinha sido laureada em 1945, Miguel Ángel Asturias receberia o Nobel em 1967, Pablo Neruda, em 1971, e, em 1982, Gabriel García Márquez. Octavio Paz (1990) e Mario Vargas Llosa (2010) seriam fenômenos posteriores. Independente das razões, é possivel afirmar, com Hobsbawm (1995, p. 485) que "nenhum leitor sério de romances podia, na década de 1970 , ter deixado de entrar em contato com a brilhante escola de escritores latino-americanos".

Nesse momento em que a indústria internacional do livro prestigiava a América Latina, soava quase uma ironia a obsessão de María Luisa Bombal em seguir reverenciando velhos nomes da velha Europa. Apesar de ter sido na Buenos Aires dos anos 1930 que a escritora encontrou a acolhida ideal para a criação artística, em entrevista radiofônica de 1972 disponível no canal da OECH (Organización de Escritoras Chilenas) no Youtube, quando questionada sobre se o ambiente que rodeia o escritor influi no seu processo criativo, ela responderia: "Não, não para mim (pausa). Salvo na França. A França me fez escritora". ${ }^{9}$ Nas entrevistas e cartas compiladas por Lucía Guerra para as Obras completas (BOMBAL, 1996), María Luisa nunca rendeu tributo a obras literárias latino-americanas, nem mesmo às de seus amigos. Ela, que nunca publicou uma linha escrita em francês, perdia-se em exageradas reminiscências à sua formação francesa, a qual evocava amiúde até mesmo para se justificar como usuária da língua espanhola nativa, tal como o fez no discurso à Academia Chilena de Lengua, em 1977, que reproduzo em tradução minha ao português:

Seja quem seja que chegue à França aos treze anos de idade para dar sequência aos estudos sentirá o feitiço de deixar-se dominar pela língua francesa. Digo isso porque foi a minha

\footnotetext{
${ }^{9}$ Tradução minha ao trecho [sonoro]: "No, no para mí. Salvo en Francia. Francia me hizo escritora". Essa fala é dita aos $9{ }^{\prime} 05^{\prime}$ ' da entrevista disponível no canal da OECH (Organización de Escritoras Chilenas) - Youtube. María Luisa Bombal Entrevista 1972. Fonte: memoriachilena.cl. Uploaded em 09/06/2011. 11'55 ' . Disponível em: <https://www.youtube.com/watch?v=2h8q5KHYOLg>. Acesso em 20 out. 2016.
} 
O norte de Sur e as condicionantes para manter-se no centro: O caso de María Luisa Bombal | 43 experiência, primeiramente no célebre convento e colégio Notre-Dame de l'Assomption, na rue de Lübeck, em Paris. Em seguida, no Liceu La Bruyère e também no Institut Catholique onde continuei os estudos a fim de obter meu diploma secundário em Línguas Latinas e no qual atingi minhas notas mais altas em... francês. Depois, e finalmente, estudei na Sorbonne, pela qual me graduei em... Literatura Francesa. $O$ francês, a língua que era então aquela em que eu vivia, falava, escrevia, a língua que eu amava e na qual acreditava que haveria de ser a minha no meu sonhado futuro como escritora... Apesar disso, durante todo aquele tempo, havia um impulso natural, algo semelhante a um segundo e secreto amor que me impulsionava a seguir lendo e escrevendo em... castelhano, por fora e a parte dos meus estudos obrigatórios (BOMBAL, 1996, p. 315).

Essa María Luisa madura e em constantes dificuldades financeiras talvez rememorasse o passado na França como um último bibelô de autoindulgência classista. Não deixa de espantar, no entanto, a obtusa pretensão de ser reconhecida como escritora latino-americana sem ler a América Latina. O provinciano fascínio de María Luisa pela Europa faz recordar o de Guillermo de Torre, um poeta espanhol de nascimento e residente na Buenos Aires dos anos 1930, casado com Norah, irmã de Borges, com o qual a chilena colecionava uma traquinagem que parecia ter muito prazer em narrar. Conforme entrevista a Lucía Guerra:

Já te contei a minha briga com Guillermo de Torre... Um dia, cheguei à casa [de Borges], e a mãe de Borges me disse: "María Luisa, não atravesses esta porta, porque Guillermo está a tua procura para matar-te..." Uma noite em que estávamos jantando, Guillermo se pôs a discursar, sem nenhuma consideração, contra os escritores latinoamericanos. Para ele, nenhum de nós valia coisa alguma... Borges já estava publicando sua poesia e eu já tinha escrito A última névoa. Então, ofendidos, perguntamos a ele quais seriam, afinal, os bons escritores. Com o seu sotaque espanholíssimo, respondeu: “Azorín! Azorín!”. Começou a nos dar uma longa lição e, por fim, subiu e nos trouxe um livro lindo do Azorín que inclusive estava dedicado. 
Quando todos foram à mesa, Borges e eu nos pusemos a corrigir o estilo, como se fosse uma prova de galera, com comentários à margem, que diziam: "Repetição", "Alterar adjetivo", "mau gosto", "erro de sintaxe". E, é claro, quando o Guillermo abriu o livro, ficou furioso e me queria matar (BOMBAL, 1996, p. 331, a tradução é minha).

O nome de Borges era mencionado com frequência por María Luisa, mas nunca a obra do amigo. Quando nem mesmo a Europa restringia-se ao europeu, María Luisa Bombal permaneceu atocaiada no rançoso cânone apreendido em sua formação francesa. Quando nem mesmo a consagração da América Latina abstinha-se do político, ela seguiu cultivando o terreno dos enredos anedóticos de enaltecimento ao compadrio forjado no compartilhamento de origens e habitus (BOURDIEU, 2001, p. 293). Quando os estudos de literatura, sobretudo a literatura comparada, iniciava o alargamento de fronteiras disciplinares (ALÓS, 2012) e a disputa de forças desequilibrava a neutralidade, quando os condicionantes de gênero, cor e classe e as afiliações políticas conformadoras da tal literatura pura começaram a ser escancaradas, María Luisa estava tão isolada que já não o podia ver. A escritora chilena que desdenhava o feminismo e afirmava não perceber subordinação nenhuma da mulher em relação ao homem - "acredito que cada um sempre esteve em seu lugar, nada mais" (BOMBAL, 1996, p. 337) - foi resgatada pela geração de pesquisadoras que promoveu a virada cultural. Em outras palavras, quando se alteraram os mecanismos de constrangimentos e recompensas e a tal pureza literária foi posta, de vez, em xeque, a literatura de Bombal voltou a angariar o interesse de acadêmicos e leitores-nãoprofissionais.

A mulher María Luisa Bombal, no entanto, não desfrutaria dessa retomada de interesse por sua obra. De 1973 até 1979, foram muitas as cartas que ela enviaria à irmã mencionando a melancolia, as dificuldades financeiras e a solidão. María Luisa retornou ao Chile para cuidar da mãe já bastante idosa, que faleceu em seguida, e precisou alugar quartos da casa onde viviam a fim de complementar a renda. Em cartas à irmã Blanca, a escritora reclamava dos hóspedes, garantia não estar bebendo, queixava-se que a filha Brigitte não telefonava nem respondia a suas cartas, fazia menções a alguma questão jurídica, mas, principalmente (ao menos nas cartas que Lucía Guerra compilou para BOMBAL, 1996), lamentava o desamparo emocional e material que marcaram seus últimos 
O norte de Sur e as condicionantes para manter-se no centro: O caso de María Luisa Bombal | 45

dias. Em 6 de maio de 1980, possivelmente a causa de doença hepática após muitos anos de alcoolismo, María Luisa Bombal faleceu sozinha, num quarto coletivo de um hospital público. Logo após a sua morte, a revista Sur lançaria seu número 347 (julho a dezembro de 1980), um dos mais célebres da história do periódico portenho: uma compilação de correspondências de Victoria Ocampo, falecida em 1979, delineava para a posteridade o sólido cabedal de relações da matriarca da cultura portenha. Não houve homenagens à chilena. Até mesmo a morte reforçaria os mecanismos de exclusão / inclusão calcados em prestígio de classe.

\section{REFERÊNCIAS:}

ALÓS, Anselmo Peres. Literatura Comparada ontem e hoje: campo epistemológico de ansiedades e incertezas. Porto Alegre, Organon (UFRGS), v. 27(52), p. 17-42, 2012.

BERNARDINI, Aurora Fornoni. Apresentação. In: BOMBAL, María Luísa. A amortalhada. Tradução de Aurora Fornoni Bernardini e Alicia Ferrari del Pardo. Revisão de Adma Muhana. São Paulo: Difel, 1986. 84p. (pp. IX - XI), X.

BIBLIOTECA NACIONAL DE CHILE. Memoria chilena. La transformación económica chilena entre 1973 - 2003. Disponível em: <http://www.memoriachilena.cl/602/w3-article-719.html>. Acesso em: 28 out. 2016.

BOMBAL, María Luísa. A amortalhada. Tradução de Aurora Fornoni Bernardini e Alicia Ferrari del Pardo. Revisão de Adma Muhana. São Paulo: Difel, 1986. 84p.

- A última névoa. Tradução de Neide T. Maia González, e revisão de Vicente Cechelero. São Paulo: Difel, 1985. 108p.

A última névoa e A amortalhada. Tradução de Laura Janina Hosiasson. São Paulo: Cosac Naify, 2013. 224p.

- Obras completas. Barcelona / Buenos Aires / México DF / Santiago de Chile: Editorial Andrés Bello, 1996. 456p.

BOURDIEU, Pierre. Génese histórica de uma estética pura. In: poder simbólico. Tradução de Fernando Tomaz. 4. ed. Rio de Janeiro: Bertrand Brasil, 2001. 322p. (p. 281 - 298).

CORREIO DA MANHÃ. 28 de janeiro de 1941. Disponível em: $<$ http://memoria.bn.br/DocReader/DocReader.aspx?bib=089842 05 \&pesq=Maria\%20Luisa\%20Bombal>. Acesso em: 20 out. 2016. 
COSTA, Walter Carlos. Uma antologia excêntrica e clássica. In: BORGES, J. L; BIOY CASARES, A.; OCAMPO, S. (Orgs.). Antologia da literatura fantástica. Tradução de Josely Vianna Baptista. São Paulo: Cosac Naify, 2013. 448p. (pp. 429-434).

GUERRA, Lucía. Mujer, cuerpo y escritura en la narrativa de María Luisa Bombal. Santiago: Ediciones Universidad Católica de Chile, 2012. $199 \mathrm{p}$.

GRAMUGLIO, Maria Teresa. Sur: uma minoria cosmopolita na periferia ocidental. Tradução de Fábio Cardoso Keinert. Tempo Social. São Paulo, v. 19, n. 1, pp. 51 - 69, jun. 2007.

HOBSBAWM, Eric. Era dos extremos: o breve século XX (1914 - 1991). Tradução de Marcos Santarrita. São Paulo: Companhia das Letras, 1995. 598p.

IMBERT, Enrique Anderson. Historia de la literatura hispanoamericana II época contemporánea. Ciudad de México: Fondo de Cultura Económica, 2000. 510p.

JORNAL DE NOTÍCIAS. 20 de fevereiro de 1949. Disponível em: <http://memoria.bn.br/docreader/DocReader.aspx?bib=583138\&pa gfis $=8401>$. Acesso em: 15 out. 2016.

KAHMANN, Andrea Cristiane. O Brasil lê María Luisa Bombal: o sistema e suas traduções. Tese defendida na Universidade Federal do Rio Grande do Sul, Programa de Pós-Graduação em Letras, Orientação de Sara Viola Rodrigues, Porto Alegre, 2017. 306f.

LARRAÑAGA, Osvaldo. El Estado de Bienestar en Chile: 1910 - 2010. Programa de las Naciones Unidas para el Desarrollo - Chile Área de Reducción de la Pobreza y la Desigualdad, 2010. 82p. p. 71. Disponível em: <http://www.cl.undp.org/content/dam/chile/docs/pobreza/undp_cl _pobreza_estado_bienestar.pdf>. Acesso em: 28 out. 2016.

MICELI, Sergio. Sonhos da periferia: inteligência argentina e mecenato privado. São Paulo: Todavia, 2018. 184p.

OECH (Organización de Escritoras Chilenas) - Canal de Youtube. María Luisa Bombal Entrevista 1972. Fonte: memoriachilena.cl. Uploaded em 09/06/2011. 11'55' '. Disponível em: <https://www.youtube.com/watch?v=2h8q5KHYOLg>. Acesso em 20 out. 2016.

OCAMPO, Victoria. Carta a Waldo Frank. Sur, revista trimestral, Buenos Aires, ano 1, verão de 1931, pp. 7 - 18. Disponível em: <http://www.cervantesvirtual.com/obra-visor/verano-1931-ao-i- 
O norte de Sur e as condicionantes para manter-se no centro: O caso de María Luisa Bombal | 47

buenos-aires/html/dcd8ed98-2dc6-11e2-b417-

000475f5bda5_3.html\#I_0_>. Acesso em: 12 mai. 2018.

PROYECTO INTERNACIONAL DE DERECHOS HUMANOS. Carlos

Ramón Bombal Otaegui: abogado informante de la DINA. Disponível em:

<http://www.memoriaviva.com/criminales/criminales_b/bombal_ota egui.htm>. Acesso em: 21 out. 2016.

SARLO, Beatriz. Modernidade periférica: Buenos Aires 1920 e 1930. Tradução de Júlio Pimentel Pinto. São Paulo: Cosac Naify, 2010. 480p.

TIBURI, Márcia. As mortas. Disponível em: <https://editora.cosacnaify.com.br/blog/?tag=maria-Luísa-bombal>. Acesso em: 2 mar. 2014.

TORRES, Marie-Hélène Catherine. Traduzir o Brasil literário: história e crítica. vol. 2. Tradução de Clarissa Prado Marini et. al. Tubarão: Copiart / PGET - UFSC, 2014. 397p.

VALLERIUS, Denise Mallmann. Borges em nova tradução: regionalismo para além das fronteiras. Porto Alegre: Editora da UFRGS, 2010. $320 \mathrm{p}$.

VERDUGO FUENTES, Waldemar. María Luisa Bombal, una huella. Santiago: Consejo Nacional de la Cultura y las Artes de Chile (Premio Escrituras de la Memoria 2011), 2013.63p.

Recebido em: 26/03/2018

Aceito em: 19/04/2018 